\title{
Y Rizoma \\ As fronteiras do fático e do ficcional nas crônicas de Luiz Ruffato no El País
}

\begin{abstract}
Resumo: A crônica, que transita entre os campos da literatura e do jornalismo, pode ser reconhecida como gênero argumentativo que tem por objetivo seduzir e envolver o leitor para atingir as intencionalidades do autor, ou do veículo para o qual ele escreve. Neste artigo, o objetivo é investigar as fronteiras entre fático e ficcional nas crônicas de Luiz Ruffato para o El País, a partir de aspectos autobiográficos apontados nos textos selecionados. A metodologia adotada é a análise crítica da narrativa.
\end{abstract}

Palavras-chave: crônicas; fático; ficcional; Luiz Ruffato.

\section{Las fronteras del fático y del ficcional en las crónicas de Luiz Ruffato en El País}

Resumen: La crónica, que transita entre los campos de la literatura y del periodismo, puede ser reconocida como género argumentativo que tiene por objetivo seducir y envolver el lector para atingir las intencionalidades del autor, o del vehículo para el cual él escribe. En este artículo, el objetivo es investigar las fronteras entre fático y ficcional en las crónicas de Luiz Ruffato para El País, a partir de aspectos autobiográficos apuntados en los textos seleccionados. La metodología adoptada es el análisis crítico de la narrativa.

Palabras clabe: crónica; fático; ficcional; Luiz Ruffato.

\section{The factual and fictional boundaries in the chronicles of Luiz Ruffato in El País}

\begin{abstract}
The chronicle, transiting between the literature and journalism fields, can be recognized as an argumentative genre that has the objective of seducing and envolving the reader to achieve the autor's intention, or of the medium that he writtes for. In this article, the objective is to investigate the boundaries of factual and fictional in the chronicles of Luiz Ruffato for $E l$ Pais, from the autobiographic aspects pointed in the selected texts. The adopted methodology is the critical analysis of the narrative.
\end{abstract}

Cláudia Albuquerque Thomé Michele Pereira Rodrigues ${ }^{2}$

${ }^{1}$ UFRJ e doutora em Ciência da Literatura pela UFRJ, professora adjunta da Faculdade de Comunicação da UFJF, colaboradora do PPGCOM/UFJF e líder do grupo de pesquisa "Mídia e Literatura" certificado pelo CNPq. E-mail: cthomereis@gmail.com.

${ }^{2}$ Bacharela em Turismo pela UFJF e mestranda em Comunicação no PPGCOM/UFJF. Membro dos grupos de pesquisa/CNPq "Mídia e Literatura" e "Comunicação, Cidade e Memória".

E-mail: michelepereiraa@gmail.com.

Keywords: chronicle; factual; fictional; Luiz Ruffato. 


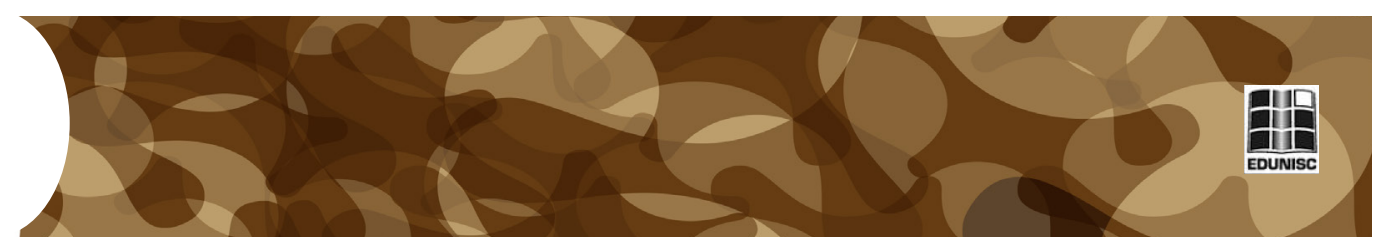

\section{Introdução}

O jogo entre o factual e a ficção na literatura sempre instigou debates acadêmicos. No jornalismo, ainda é perceptível certa resistência em reconhecer o texto jornalístico como narrativa construída a partir de elementos subjetivos como, por exemplo, o recorte que se pretende adotar ou a escolha de sintagmas mais adequados em determinadas circunstâncias.

A crônica, enquanto gênero na fronteira entre esses campos, consolidou-se no Brasil como um espaço que suporta uma grande variedade de temas, originando textos de diferentes tipos, que vão desde uma história contada pelo cronista, fática ou não, podendo passar por uma reflexão sobre a vida, ser um comentário e até mesmo uma análise sobre política ou economia. Como narrativa que é, pode ser reconhecida pelo seu potencial argumentativo que tem por objetivo seduzir e envolver o leitor nas intencionalidades do autor, considerando também o que este receptor constrói na fruição do texto.

Nesse contexto, os jornais de maior circulação têm buscado manter um conjunto de jornalistas, escritores, intelectuais e especialistas, escrevendo, na maioria das vezes, em seus cadernos de Opinião, hoje como alternativa à crescente queda nas vendas dos impressos ${ }^{3}$. Como este pode ser considerado um dos poucos espaços nos jornais livres do gatekeeper, dependendo do maior ou menor grau de liberdade concedido pelo veículo, comumente projeta o nome do cronista como formador de opinião, em tempos que há muita informação disponível, mas a profundidade da reflexão nem sempre está garantida.

Operando desde 2013 no Brasil, o jornal El País, de origem espanhola, não foge desta realidade. Um de seus vários colunistas é Luiz Ruffato, escritor consagrado pela crítica e ganhador de diversos prêmios a nível nacional e internacional em função de seus romances. Ruffato é reconhecido, entre outros aspectos, por seu tom crítico em relação ao Brasil especialmente no que tange à política e a questões sociais.

No estudo da narrativa, foco da presente pesquisa, curioso é observar situações em que o autor da crônica se coloca enquanto personagem das ações que narra. Muitas vezes, ele parte de situações particulares para refletir sobre problemas da sociedade em geral, quase como se fizesse um esforço autobiográfico. Como a construção deste texto se dá? Quais são os elementos intencionalmente ou não invocados para a reconstituição dessa memória narrada?

Este artigo tem por objetivo investigar as fronteiras entre o fático e o ficcional nas crônicas de Luiz Ruffato para o El País, através de aspectos autobiográficos utilizados pelo autor nestes textos, levando em conta o contexto da midiatização do jornalismo, caracterizado pela dialogia e pela atorização, como apontado por SOSTER (2013). Almeja-se contribuir com a reflexão sobre o papel do autor atualmente, considerando esse contexto mi-
${ }^{3}$ Diz-se hoje porque não é recente a experiência de escritores se aventurando como cronistas. Nomes consagrados da literatura nacional como, por exemplo, Machado de Assis, Lima Barreto e Olavo Bilac contribuíram para a consolidação do gênero no Brasil, como reforça Reis

(2013). 

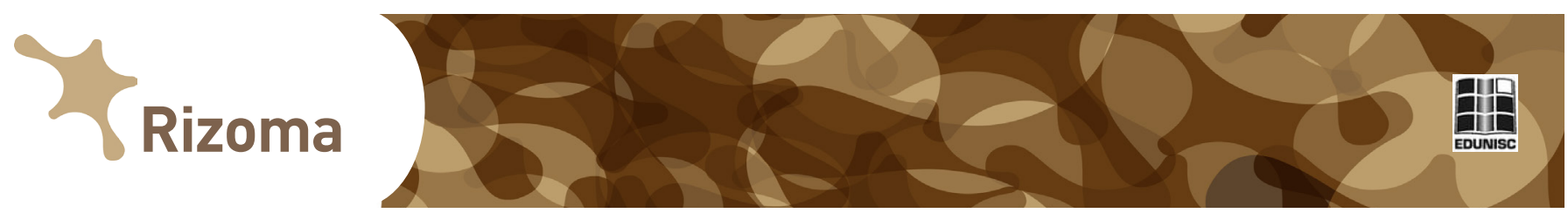

diatizado em que vivemos e as transformações recentes no campo do jornalismo, além de tecer observações sobre o papel da crônica enquanto mais um espaço para a reprodução da imagem desse autor, que passa a ser também um formador de opinião. $\mathrm{O}$ percurso metodológico adotado será a análise crítica da narrativa, de Motta (2013).

\section{Ruffato no El País}

Luiz Ruffato nasceu em Cataguases, município do interior de Minas Gerais, em 1961. Trabalhou em diversos ofícios até se formar em jornalismo pela Faculdade de Comunicação da UFJF. Exerceu a profissão durante 13 anos em Juiz de Fora, Alfenas e na capital paulista como editor e redator no jornal "O Estado de São Paulo". Declarou-se escritor profissional em 2003 e, desde então, seus romances, consagrados pela crítica, têm se dedicado aos desafios e conflitos da vida nas cidades, mais detidamente à representação da periferia e de personagens marginalizados, temática que posteriormente se estendeu às suas crônicas.

Ganhador de diversos prêmios com os romances "Eles eram muitos cavalos" (que se passa em São Paulo) e "Inferno Provisório" (que traz, entre seus cenários, a cidade de Cataguases), Ruffato recebeu destaque no contexto da literatura brasileira contemporânea. Isso se dá, segundo Castro (2010), porque o modelo narrativo de Ruffato rompe com o romance tradicional. Na orelha do volume I da coleção "Inferno Provisório", escrita por Cecília Almeida Salles, lê-se:

É interessante observar que o autor nos apresenta textos onde as sequências de ações perdem o poder canônico de contar histórias e adquirem a natureza de descrições. Nos defrontamos, assim, com narrações de eventos onde quase nada acontece. Oferecem, porém, retratos acurados de personagens que compõem uma sociedade em agonia. (SALLES, 2005, orelha do livro).

Importa salientar que, para Motta (2013), na construção das narrativas, os autores fazem uso de dispositivos discursivos de acordo com suas intenções. Ao construir uma narrativa, seja sobre a história de um país ou sobre aspectos do cotidiano de um personagem, o que se conta é uma versão daquela história, pautada em ideologias e intenções particulares.

Ruffato não esconde a bandeira que carrega. Em diversas entrevistas ${ }^{4}$, afirma que sua obra reflete uma decisão política de representar personagens à margem do processo de desenvolvimento do país, universo no qual ele mesmo se insere por conta de sua trajetória de vida. Nesse sentido, tanto nas crônicas como em seus romances, busca explorar o efeito de real (BARTHES, 1972), a ponto de nem sempre deixar claro para o leitor a veracidade dos fatos narrados. Isso faz com que o leitor ganhe um papel central nesta construção, já prevista pelo pesquisador, sobretudo quando afirma que "o verossímel nada mais é que o opinável: está inteiramente sujeito à opinião (do público)" (BARTHES, 1972, p. 42). 

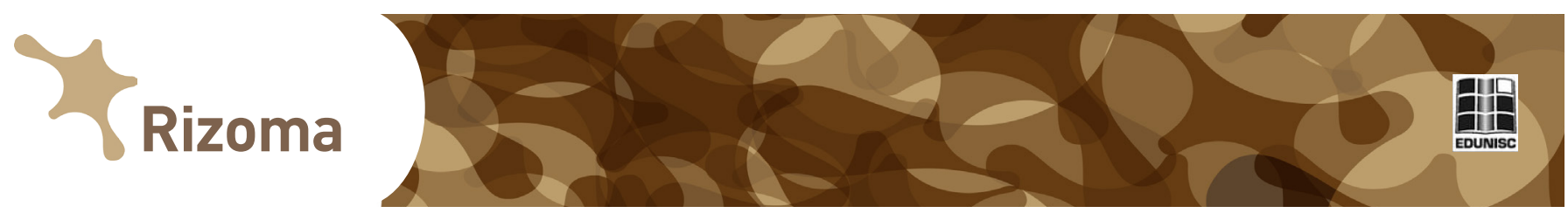

Em alguns momentos, durante a leitura de seus romances, é possível questionar se o próprio autor não seria um dos personagens envolvidos nas tramas, especialmente quando o cenário é a cidade em que viveu sua infância e adolescência e quando suas narrativas contam situações que poderiam ter acontecido com ele, considerando os locais que morou e trabalhou e as circunstâncias que viveu. Todavia, ele adverte o contrário: "Evidentemente, a minha Cataguases é ficção. As ruas, praças e pessoas que cito existem para mim, embora calcadas no espaço real" (RUFFATO, 2007, p. 211). Silva (2012, s/n), ao tratar desse jogo entre real e fictício, sustenta que, de forma paradoxal, "ficção, como mentira que é, permite, quando boa, chegar mais profundamente a uma verdade".

Com todo esse reconhecimento no campo do romance, a trajetória de cronista do autor começa no El País junto com o lançamento da edição brasileira do jornal, em 26 de novembro de $2013^{5}$. Ruffato assumia a coluna semanal no caderno Opiniões cerca de dois meses após o discurso polêmico na Feira do Livro de Frankfurt ${ }^{6}$ que ecoou na mídia brasileira, gerando debates acirrados entre os que eram ou não a favor do tom crítico adotado por ele em relação ao Brasil.

\section{Crônica como gênero de fronteira}

De acordo com Sodré (2009), ao jornalista, tradicionalmente, é atribuída a chancela de noticiar a verdade. A despeito disso, frisa que o jornalismo não é reflexo da sociedade, mas construção social de uma realidade específica, em que as condições de produção de um jornal, como, por exemplo, o espaço delimitado e o prazo de entrega, além dos pontos de vista do autor, influenciam em cada escrita. Há, nesse campo, portanto, um mito de imparcialidade, presumindo que existe um real verdadeiro a ser descrito. Neste ponto, Sodré (2009) afirma que o jornalismo pode ser ficcional, mas não fictício.

O que é fictício, para ele, é a literatura, que pode ser caracterizada como expressão da subjetividade. Desse modo, esses dois gêneros textuais não são estanques, tese corroborada por Motta (2013), para quem as fronteiras entre uma narrativa realista e outra imaginária nunca são claras e definitivas.

Aristóteles (2000), em sua Poética, trata do artifício do narrar como mimese. $\mathrm{O}$ conceito, que tem como origem a imitação da realidade, pode ser entendido como um processo de apropriação do mundo, em que o homem faz uma leitura da realidade a partir de seus pontos de vista. Ou seja, a maneira como o narrador constrói sua narrativa, seja o recorte que adota sobre um fato ou a sua linguagem, sempre está contaminada por sua visão de mundo e busca atender aos objetivos para os quais foi construída. Assim, a narrativa nunca é neutra em sua plenitude.

Mesmo a memória, que pode ser entendida, a partir de teóricos como Huyssen (2000), como um emaranhado de lembranças e esquecimentos eivados das fantasias pessoais, projeções e lembranças de outras pessoas, é
5 A versão online do jornal pode ser acessada em: http://brasil.elpais. com/. Todas as crônicas em exame neste trabalho foram consultadas através da página do jornal na internet.

${ }^{6}$ A íntegra do discurso proferido na Feira Literária de Frankfurt pode ser lido em: http://cultura. estadao.com.br/noticias/geral,leia-a-integra-do-discurso-de-luiz-ruffato-na-abertura-da-feira-do-livro-de-frankfurt,1083463. Acesso em: 18/08/2016. A fala de Ruffato no evento denota uma crítica às contradições e desigualdades sociais brasileiras. A repercussão foi grande tanto na imprensa nacional, como nas redes sociais online. 

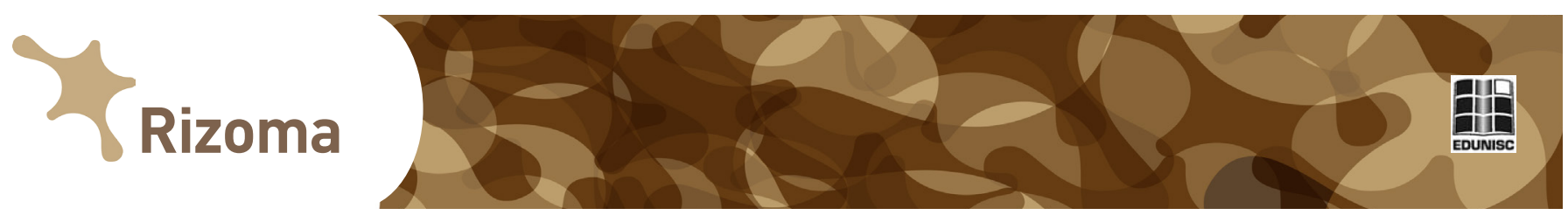

resultado das diversas disputas de poder existentes na contemporaneidade sobre o consciente e o inconsciente do indivíduo.

Seria mais adequado, então, na visão tanto de Motta (2013) como de Sodré (2009) que, ao invés de tratar a narrativa como real ou não, que buscássemos identificá-la a partir das marcas de enunciação presentes no texto. Motta (2013) adota, assim, a classificação das narrativas como fáticas, quando reivindicam uma fidelidade ao real, como, por exemplo, o jornalismo e a ciência, e ficcionais, quando há uma suspensão temporária das descrenças, como acontece com a literatura, o cinema, entre outros. A essa última, basta que seja verossímil (MOTTA, 2013), isto é, que seja possível dentro da lógica interna do universo em que o enredo se desenvolve.

A crônica, enquanto gênero de fronteira entre jornalismo e literatura, consolidou-se no Brasil como um espaço que suporta uma grande variedade de textos. Por excelência, de acordo com Resende (2001), é um gênero de representação do urbano. Tem como característica principal o fato de ser publicada originalmente em jornais, ainda que existam livros que são coletâneas de crônicas. O processo criativo do cronista deve obedecer então à lógica jornalística: seu espaço é delimitado e há um prazo de entrega. Isso imprime um caráter efêmero à crônica e requer do cronista a habilidade de concisão. Fala diretamente ao leitor e, assim, por vezes, faz uso de linguagem coloquial, segundo Arrigucci Júnior (1987).

Em relação aos outros textos dos jornais, esse é um dos únicos espaços que podem estar livres de gatekeeper, adverte Reis (2015). Logo, veiculadas em jornais de grande circulação, como no caso do El País, por exemplo, as crônicas projetam o nome do cronista, fazendo com que ele se torne também um formador de opinião. Além disso, ainda que os jornais ressaltem que o texto é de total responsabilidade do escritor, o leitor reconhece ali certo aval do jornal ao conceder um espaço em suas páginas àquele cronista.

Isso foi um problema no decorrer do século XX. Diversos escritores dos quais é possível citar, a título de exemplo, Nelson Rodrigues e Clarice Lispector, reconhecidos pelo cânone literário, comumente escreviam para os jornais adotando pseudônimos. Nesse período a crônica era um meio de obter recursos financeiros, situação que, por muitos anos, fez com que o gênero fosse entendido como menor. Hoje, escrever crônica é sinal de prestígio. Em um contexto midiatizado, é mais um suporte desse autor que busca estar na mídia. Além disso, dentro do que se considera a midiatização do jornalismo, a crônica ganha peso por ser um gênero que pressupõe a dialogia que, segundo Soster (2013, p. 13), está presente na seguinte situação:

É quando o jornalismo, por exemplo, vai buscar na literatura subsídios para estabelecer diferenças, reconfigurando-se nas instâncias de emissão, recepção, circulação e reconhecimento, ou quando, dialogicamente, a literatura passa a se valer de lógicas comunicacionais para dar conta de seus processos.

Ainda na configuração da crônica como gênero jornalístico, é fundamental enfatizar também a presença da atorização, nos termos de Soster (2013), outra característica do jornalismo midiatizado, que dialoga com a 

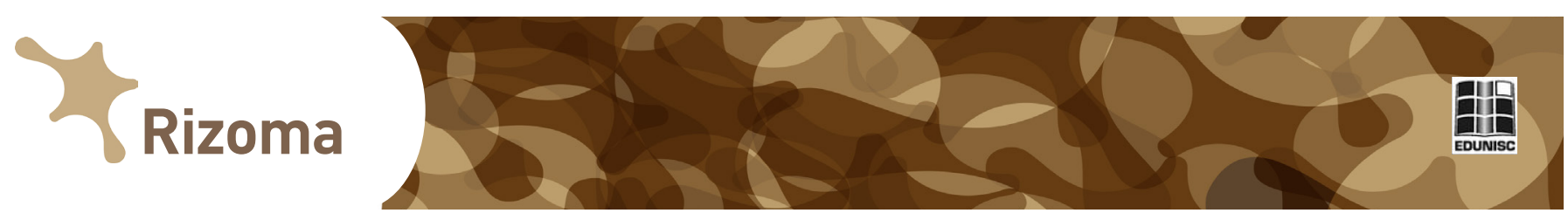

análise aqui presente: o jornalista passa a "realizar novas ofertas de sentido a partir de sua percepção particular dos acontecimentos" (SOSTER, 2013, p. 13). E é isso que acontece na crônica. Voltemo-nos então, a entender esse papel do narrador presente no texto.

\section{O narrador e o personagem no contexto da atorização}

Benjamin (1994) tem uma das mais importantes colaborações quando se trata do papel do narrador. Segundo ele, uma experiência de vida concede a um sujeito autoridade para criar uma narrativa sobre o que lhe ocorreu. $\mathrm{Na}$ sociedade cada vez mais midiatizada, no entanto, há uma valorização do que Santiago (2002, p. 38) chama de narrador pós-moderno, "aquele que quer extrair a si da ação narrada, em atitude semelhante à de um repórter ou de um espectador".

No entanto, para Figueiredo (2010), o modelo narrativo do autor presente vem ganhando força, o que justificaria o uso recorrente de elementos autobiográficos nos textos: "aquilo que mais se aproxima do real, ou o que leva a chancela do real, como tudo que é raridade, passa a ser extremamente valorizado" (FIGUEIREDO, 2010, p. 77). Na imprensa, por exemplo, é comum que as reportagens tragam entrevistas realizadas com personagens que tenham passado pela situação noticiada ou até mesmo que mostrem que o próprio jornalista esteve no local e vivenciou de certa forma aquilo que narra. Sobre este aspecto, Sodré $(2009$, p. 48$)$ aponta que a credibilidade desse tipo de reportagem "[...] decorre muito provavelmente do lugar privilegiado que o jornalista ocupa como mediador entre a cena do acontecimento e a sociedade global: o lugar da testemunha".

De acordo com Lejeune (2008), uma das principais características do autor atualmente está ligada à influência da mídia. Sua presença na TV, na internet ou nos impressos, tecendo comentários sobre sua obra ou até mesmo em relação a assuntos triviais, faz dele personagem de uma nova narrativa, paralela àquilo que escreve, o que, por vezes, cria no leitor certa afetividade, que o leva a acompanhar este autor. Além disso, ter um livro publicado faz do autor um exemplo de êxito social (LEJEUNE, 2008), mas não o exime da busca para cooptar novos leitores: "O autor de hoje deve induzir o desejo de ler seus textos, ao passo que antes, era o texto que despertava a vontade de se aproximar dele" (LEJEUNE, 2008, p. 199). Dessa forma, a persona do autor pode se tornar um chamariz para aquilo que ele escreve, subvertendo a ordem tradicional da narrativa, na qual a mão do autor sai de cena, de acordo com Barthes (2004).

Em que pese a construção imagética do próprio autor sobre si mesmo, a imagem que temos dele depende também do enquadramento que a mídia o confere. No caso de Ruffato, ao posicionar-se indicando um projeto político que perpassa sua escrita, tornando-o público, busca construir uma imagem de autor engajado, que tem como principal mote a representação do trabalhador brasileiro. Sua imagem equivale à de um defensor dos cidadãos frente 


\section{Yizoma}

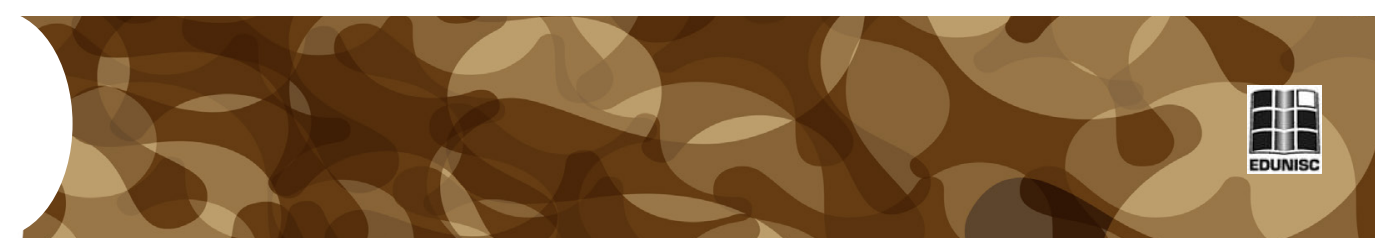

às mazelas que sofrem, denunciando-as todas as vezes que tem espaço para isso. Candido (1992) chama esse modelo de escrita militante.

Embora Candido (1992) afirme que, em sua origem, a crônica tinha intensão de informar e comentar, tomando forma de texto leve, mais alinhado ao entretenimento, é possível identificar, por exemplo, o sucesso das crônicas de Lima Barreto, já nos anos 1920, com estilo crítico, ácido e irônico, denunciando, por vezes, as dificuldades da população mais pobre da cidade do Rio de Janeiro.

Há que se considerar, ainda, o papel do leitor no processo narrativo. Para Motta (2013), o discurso produz efeitos consciente e inconscientemente desejados. Isso se dá porque, segundo Certeau (1994), o leitor não é sujeito passivo: ele se apropria de um produto cultural e faz uma leitura desse bem. Dessa forma, Certeau (1994) cita a "Sociedade do Espetáculo" de Guy Debord (1967), onde há uma subversão da oposição entre produção e consumo, na qual o leitor passa a ser encarado também como produtor de sentido no ato de ler.

\section{Análise das crônicas}

O primeiro passo em direção à aplicação da análise crítica da narrativa neste trabalho foi a seleção da amostra dentro do universo de crônicas de Ruffato para o El País. No período de 26/11/2013 a 20/07/2016 foram contabilizados 140 textos publicados na coluna que leva o nome do autor. Em seguida, buscou-se identificar as crônicas em que Ruffato se mostra presente no texto enquanto um narrador que também é personagem das narrativas que constrói. Para isso, a opção adotada foi dividir os textos em categorias, assim distribuídas:

Tabela 1: Classificação das crônicas

\begin{tabular}{|c|c|c|c|c|}
\hline \multirow{2}{*}{$\begin{array}{c}\text { Tipos de } \\
\text { crônica }\end{array}$} & Autobiográfico & \multirow{2}{*}{ Ficcional } & \multicolumn{2}{|c|}{ Opinativo } \\
\cline { 4 - 5 } & & & Autobiográfico & Informacional \\
\hline $\mathrm{N}^{\mathrm{o}}$ de textos & 36 & 2 & 24 & 78 \\
\hline Porcentagem & $25,71 \%$ & $1,42 \%$ & $17,14 \%$ & $55,71 \%$ \\
\hline
\end{tabular}

Fonte: Elaboração dos autores

As categorias acima estão embasadas naquelas sugeridas por Afrânio Coutinho em "A Literatura no Brasill", Antônio Candido em "A vida ao rés do chão" e Luiz Beltrão em "Jornalismo Opinativo". A despeito de não tratarem diretamente do objeto deste trabalho, esses teóricos são referências no tocante ao estudo sobre crônica brasileira e, dessa forma, são adotados como norteadores para a categorização aqui proposta. A partir deles e de uma análise prévia do objeto proposto, foi possível então dividir as crônicas de Ruffato no período analisado em autobiográficas, ficcionais e opinativas. Estas 

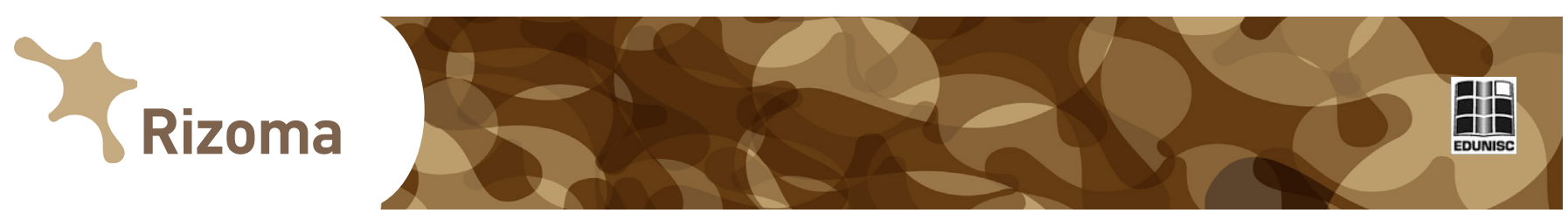

últimas apresentam duas subcategorias, como será explicitado mais adiante.

A crônica chamada de autobiográfica apoia-se no que Coutinho (1971) chama de "Crônica Metafísica" que consiste em reflexões sobre acontecimentos e pessoas, de cunho mais ou menos filosófico. Já o que chamamos aqui de "narrativa mais ficcional" pode ser reconhecida, na obra de Candido (1992) e também na de Coutinho (1971), com o mesmo nome, "Crônica Narrativa", com características próximas ao conto contemporâneo. São textos em que o cronista conta uma história, com personagens, sem estar necessariamente ancorado no cotidiano do leitor, mas muitas vezes trazendo reflexões a respeito dele.

O último tipo, denominado aqui de "Opinativo", principalmente na categoria informacional, é descrito por Beltrão (1980) como "Analítica" e se caracteriza pelo emprego de um tom mais sério, linguagem sóbria e enérgica, em que os fatos são expostos e analisados com objetividade. Pode ser comparada também à "Crônica Informação" de Afrânio Coutinho, não obstante esse autor considere que os comentários produzidos aqui sejam impessoais. Esse último tipo foi dividido ainda em duas subcategorias: opinativo informacional e opinativo autobiográfico. $\mathrm{O}$ texto foi enquadrado como "Opinativo informacional" quando Ruffato analisa dados sociais, políticos e econômicos e expõe sua opinião sobre eles e como "Opinativo Autobiográfico" quando cita casos que teriam ocorrido com ele, mas que refletem uma situação partilhada por outras pessoas. Aqui, o caso particular é um gatilho para chamar atenção para a reflexão que ele pretende traçar, portanto, é um elemento secundário.

Após essa classificação, foi possível identificar que Ruffato é um autor de crônicas predominantemente opinativas. São 78 textos, o que corresponde a quase $56 \%$ do total, em que o autor expõe seus pontos de vista principalmente em relação à sociedade brasileira, abordando temas como violência, racismo e machismo. Somados a esses, podemos destacar os textos em que Ruffato parte de uma experiência própria para refletir sobre problemas que atingem a sociedade como um todo. São 24 textos, cerca de 17\%. Há ainda dois textos (aproximadamente 1\%) que podem ser classificados como narrativas que se aproximam do conto, por serem mais ficcionais. Por fim, identificamos 36 textos, $26 \%$, em que o autor se dedica a relatar uma situação ocorrida com ele.

Apesar de em menor número, as crônicas em que o autor se insere são objeto de análise neste trabalho, em função do objetivo de rastrear as estratégias narrativas do cronista, que é jornalista, mas que recorre à ficção e à sua biografia, ou que simula isso. $\mathrm{O}$ foco do trabalho será delimitar as fronteiras entre fático e ficcional neste universo de crônicas

Sendo assim, dentre as 36 crônicas identificadas como autobiográficas, optamos por selecionar 5 textos como recorte para análise no presente artigo. São eles: "A biblioteca que virou pó", publicada em 11/02/2014, "Voando pelos ares", de 01/04/2014, "Sabedoria vegetal", de 26/01/2015, "O dia mais triste da minha vida", de 31/03/2015 e "Sinto Falta", de 17/02/2016. 

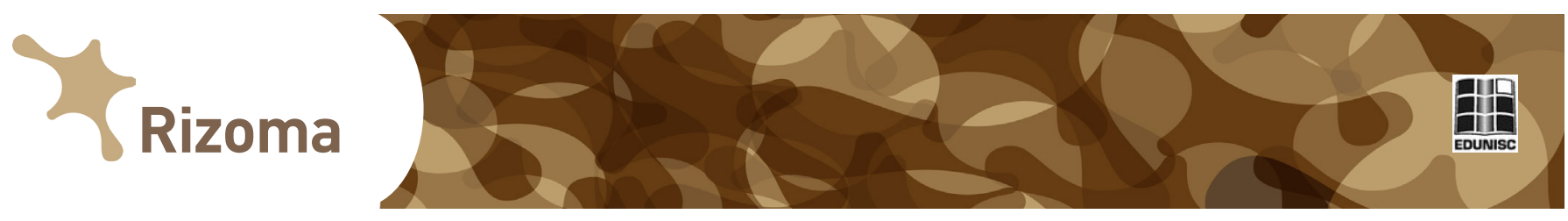

A partir dessa classificação, Motta (2013) sugere que seja feita uma divisão das instâncias do discurso narrativo. Nesse esquema, separam-se: 1) o plano da expressão; 2) o plano da estória e; 3) o plano da narrativa, a partir de sete movimentos. Para o autor, é necessário que identifiquemos no corpus de análise pontos que ajudem a decodificar a narrativa, como, por exemplo, a sequência lógica dos textos, identificando seus pontos de virada, suas conexões, as microssequências (luta, traição, sedução), o uso de recursos de linguagem, os dêiticos, os pressupostos interpretativos, situações de conflito, criação do efeito de real e o uso de designantes do personagem (seus cargos e funções).

Nos textos selecionados, onde busca-se identificar a criação do efeito de real por parte do autor, nota-se o uso frequente de recursos que ancoram a narrativa no mundo dito real, como por exemplo, em "A biblioteca que virou pó", onde Ruffato faz referência a uma data e a locais reais, como São Paulo e o bairro Taquara Preta, em Cataguases.

Descobri, frustrado, que os livros que havia adquirido ao longo de toda minha vida - estamos falando de fins dos anos 1990 - não caberiam no apartamento para onde estava me mudando em São Paulo, pequeno e mal arejado. Após inúmeras noites sem dormir, percebi que a melhor maneira de me desvencilhar deles, sem perdê-los de vista, seria organizar uma biblioteca na Taquara Preta, bairro operário de Cataguases, onde moravam meus pais. (RUFFATO, $\left.2014^{\mathrm{a}}, \mathrm{s} / \mathrm{n}\right)$.

O desfecho dessa história merece atenção: após a instalação da biblioteca no bairro, sob os cuidados de seu pai, começa uma intensa movimentação de pessoas em busca dos livros, o que acaba por incomodar os traficantes de drogas da região. A alegação é de que a biblioteca estaria atrapalhando seus "negócios". Em pouco tempo, eles exigem a interrupção das atividades. Ruffato jamais reouve seus livros, que ficaram trancados na sala da qual somente os traficantes tinham acesso.

O recurso da datação é novamente explorado nesse excerto de "Voando pelos ares", em que Ruffato revela as dificuldades financeiras da família. Veículo mais comum utilizado para ir ao trabalho em Cataguases, a bicicleta era um sonho do menino.

Meu irmão conseguiu emprestado uma Philips preta com frisos dourados, freio contra-pedal, com um colega, Tainha, que encontrava-se encostado por causa de um problema na coluna - bico de - papagaio, uma dessas doenças que, mudando de nome, mudou também de endereço. Eu a usei por três meses, o suficiente para juntar dinheiro para dar entrada na compra de uma zero quilômetro. Na loja do Ulisses escolhi, olhos de amante, a marca (Monark), a cor (laranja), o modelo (aro 26, barra reforçada) e a forma de pagamento (12 prestações fixas). [...] O dia 23 de dezembro de 1976 caiu numa quinta-feira. Eu guardei minha bicicleta no pequeno galpão coberto de folhas de amianto, no quintal. À noite, ribombaram trovões, denunciando a tempestade. O calor e a umidade afugentavam os sonhos. Devia passar da meia-noite quando o vento, sacudindo os galhos das árvores, arrancou as mudas de roupas do varal, espalhou a poeira das ruas descalças. Ouvi estranhos barulhos, mas na escuridão tudo se move com demasiado desespero. Dia seguinte, acordei com minha mãe me convocando para o mingau 


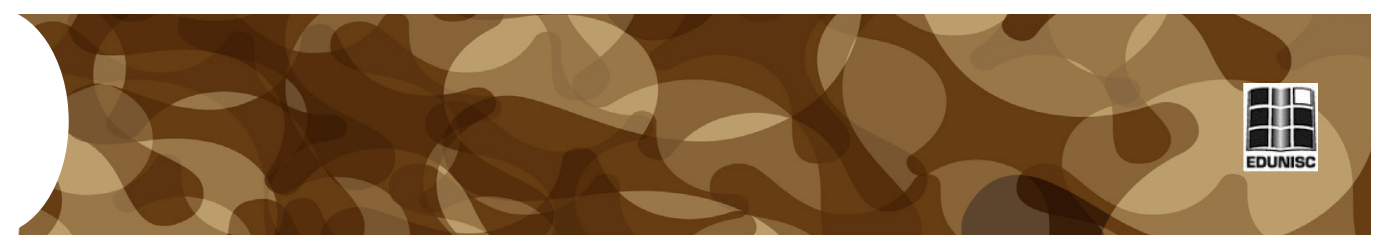

de fubá com ovo, nosso café da manhã. Espreguicei, espiei pela janela e ela não estava lá. Por um momento, meu coração parou de bater. Meu pai perguntou o que havia acontecido, não respondi. Eu me tornara adulto. (RUFFATO, 2014, s/n).

Chama a atenção também a descrição detalhada dos acontecimentos. A ambientação criada pelo autor, narrando em primeira pessoa, leva ao clímax do texto, isto é, o momento em que ele percebe que a bicicleta, que acabara de comprar, havia desaparecido da garagem de casa. Não há uma resolução do conflito. A delinquência, fruto das desigualdades apontadas por Ruffato em diversos de seus textos classificados anteriormente como opinativos, é mostrada de forma seca.

$\mathrm{Na}$ crônica "O dia mais triste de minha vida", publicada no El País em 31/03/2015, novamente a riqueza de detalhes é explorada, relatando os momentos que sucederam a morte de seu tio. $\mathrm{O}$ vazio provocado pela morte é preenchido pela observação da atmosfera triste, retratada por Ruffato:

\begin{abstract}
O irmão caçula da minha mãe, Olavo, havia sofrido um acidente estúpido e morrera de forma quase instantânea, deixando em dificuldades a mulher e uma cadeia de filhos pequenos. Tomamos um carro de praça e nos dirigimos a Rodeiro, a pequena colônia italiana de onde provínhamos. Confuso, observei de longe o tumulto do velório, a desolação na missa de corpo presente, a dor durante o cortejo da igreja ao cemitério, o desespero na hora da despedida final, a melancolia da volta para casa. A noite desabou sobre a cidade, e, por deferência, nem os cães ladravam, nem os saguis da praça São Sebastião guinchavam, nem as crianças resmungavam - até os galos adiaram a instauração da manhã. (RUFFATO, 2015 a s/n).
\end{abstract}

Novamente ancorado no espaço-tempo real, em "Sinto falta", Ruffato relembra a morte de seu irmão, num movimento chamado por Motta (2013) de analepse ${ }^{7}$. Repleto de adjetivos (pequeno, terrível, triste, estúpido, entre outros), o trecho expõe o incômodo do autor diante do enfrentamento da situação vivida.

O meu último aniversário passei sozinho no pequeno aeroporto de Ljubliana, na Eslovênia, aguardando um voo para Skopje, na Macedônia. Sentado numa desconfortável cadeira, mirando as montanhas que compõem o maciço dos pré-Alpes, percebi de repente quão longe me encontrava de tudo e de todos e o quanto isso me pesava os ombros. Num vislumbre, vi meu rosto refletido no vidro da ampla janela, espectro estilhaçado pela luz do começo de tarde. E nele reconheci a passagem do tempo, essa terrível abstração concreta - a areia já se acumula, inexorável, no porão da minha ampulheta. Vasculhei um lado e outro procurando enxergar minha mãe e por um momento senti seus dedos afagando meus cabelos - senti até mesmo o cheiro de sabão em pó, anil e água sanitária que usava para lavar trouxas e mais trouxas de roupa para fora. Ali estavam novamente seus castanhos olhos tristes - olhos que perderam o viço quando meu irmão morreu, aos 26 anos, em um estúpido acidente. Tenho certeza que ela morreu junto com ele - apenas permaneceu entre nós arrastando os dias como alguém condenado à prisão perpétua conta as horas: sem esperança. De meu irmão guardo recordações esparsas, em particular um longo diálogo havido em cima da laje da nossa casa recém-construída, em Cataguases, na Zona da Mata mineira. Ele chegara do trabalho, e após trocar de roupa me chamou para ajudar a lavar a caixa-d'água. Enquanto a esvaziávamos, conversáva-
7 Chamamos de analepse "todo movimento temporal retrospectivo destinado a relatar eventos anteriores ao presente da ação, ou até anteriores ao seu início" (MOTTA, 2013, p. 142). Na linguagem cinematográfica corresponde ao flashback. 


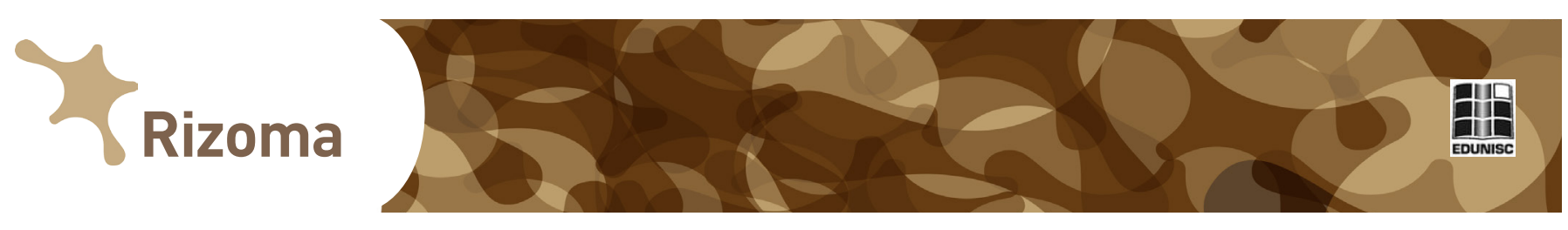

mos. Ele, 25 anos, casado de pouco, encarregado-geral da fiação de uma fábrica de tecidos; eu, 16 anos, erupção de espinhas no rosto, estudante de tornearia-mecânica no Senai... Sem que déssemos conta o sábado se pôs e, mergulhados na escuridão, nossas palavras se dissipavam rumo às estrelas que pulsavam penduradas no firmamento... (RUFFATO, 2016, s/n).

O fragmento revela uma inquietação tratada de maneira recorrente na obra de Ruffato: a questão do desenraizamento. Percebendo-se distante de todas as suas referências, sozinho, em seu aniversário, emerge a reflexão sobre sua vida e a lembrança das pessoas que já se foram. A morte do irmão, descrita nesse texto e mencionada em outros momentos da obra de Ruffato, pode ser qualificada, de acordo com Motta (2013), como ponto de virada no enredo, pois é a partir desse episódio que sua mãe perde a alegria de viver.

Ao mesmo tempo, essa narrativa remete à cidade de Cataguases, revelando traços do cotidiano de seus moradores, principalmente das famílias ligadas às fábricas locais. Esses rastros de memória são valiosos registros tanto para os que conhecem a cidade retratada quanto para os que não a conhecem e podem, a partir dessas representações, construir um imaginário sobre a cidade.

Em outro trecho, Ruffato descreve um voo metafórico, em que se percebe uma cidade voltada para a industrialização, com bairros operários e tecelagens. O uso de figuras de linguagem é comum nas crônicas do autor, como pode ser percebido a seguir:

\footnotetext{
Em casa, aguardando o pagamento, a insônia incendiava meu corpo noturno. Dia seguinte, acordava ao primeiro galo, pegava a Göricke e, peito estufado de felicidade, dirigia-me à Praça da Estação para comprar o Jornal do Brasil e O Cataguases. Eu não pedalava uma bicicleta - eu me equilibrava sobre um tapete que voava por sobre os bairros operários, planava sobre o telhado das tecelagens, sumia entre as nuvens de que se nutria o tempo. (RUFFATO, 2014).
}

A memória do cronista traz ainda informações de uma época em que era possível, por exemplo, comprar o Jornal do Brasil na banca. Novamente, a situação financeira vivida por ele é exposta, que dizia perder o sono "aguardando o pagamento".

Por fim, outra característica da crônica que é possível identificar nos textos analisados é o diálogo com o seu leitor. Em "Sinto falta", por exemplo, ele dedica o texto a Kledir Ramil, sem esclarecer de quem se trata, como se dissesse que essa pessoa entende sobre o assunto que será tratado no texto. Em "Sabedoria Vegetal", publicada em 26/01/2015, no El País, acontece algo parecido, porém, desta vez, Ruffato fala de forma mais geral aos seus leitores: "E compartilho com o leitor esse conhecimento que acredito milenar, pois a manga, originária do sudeste asiático, já é citada em poemas clássicos indianos do século IV a.C. ..." (RUFFATO, 2015a, s/n). A estrutura que simula um diálogo com o leitor é também uma estratégia que aproxima o interlocutor e que traz o autor para a cena, colocando-o como alguém que conversa ou comenta o assunto da crônica. 


\section{Sizoma}

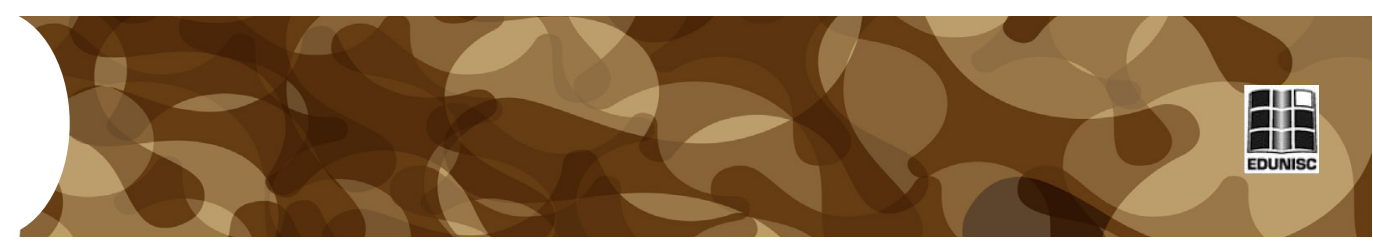

\section{Considerações Finais}

Retomando o objetivo principal deste estudo, percebe-se que, apesar de mais de $50 \%$ de seus escritos serem classificados como textos de opinião, Ruffato é um autor que, frequentemente, explora os limites entre o que é fático e o que é ficcional em suas crônicas, principalmente ao lidar com aspectos autobiográficos. Em tempos em que os autores buscam estar na mídia, seja discutindo questões relacionadas à sua obra ou não, os jornais são importantes meios para a divulgação de suas ideias e para a formação de sua imagem.

Ruffato não se furta de expor sua opinião sobre os acontecimentos políticos e sociais relevantes da história recente do país. Contudo, é digna de nota a recorrência de aspectos autobiográficos que perpassam sua obra. Suas vivências pessoais, como ele mesmo destaca, pouco exploradas na literatura brasileira, indicam um filão de mercado valorizado na contemporaneidade. Assim, é possível observar certa continuidade temática e uma coerência no projeto dramático do autor, partindo dos romances até as crônicas, resguardadas as características que definem cada um desses gêneros, fenômeno que Figueiredo (2010) chama de deslizamento das narrativas de um suporte ao outro. A estratégia de marcar seu local de fala demonstra uma expertise do jornalista, que, não raro, apresenta personagens para contar como um problema social afeta sua vida em particular.

Em suma, o plano da metanarrativa na obra de Ruffato pode ser identificado como uma tentativa de representar personagens à margem do processo de desenvolvimento do país, universo no qual ele mesmo se insere por conta de sua trajetória de vida recorrentemente tratada em seus textos. A combinação de textos factuais e ficcionais evidencia que os desafios da sociedade em geral refletem no cotidiano de cada um. A violência, a falta de dinheiro e o sentimento de desenraizamento são problemas que se humanizam quando tratados na esfera da vida particular. A memória da cidade mineira de Cataguases, presente no texto estampado na página do El País, a partir da narrativa do cronista, ajuda, entre outros recursos, na construção de seu discurso e sua legitimação.

Sendo assim, a crônica hoje tende a ser um espaço privilegiado e também de consagração do autor. A periodicidade de sua publicação no jornal $E l$ País, que geralmente é semanal, permite ao cronista um tempo de dedicação ao texto maior do que aquele exigido no jornalismo diário, que pode lhe garantir refinamento na escrita. Mesmo constituindo um gênero autônomo, ora absorvendo atributos da literatura, ora se aproximando do jornalismo, deve ser levada em consideração a amplitude de possibilidades textuais da crônica para que ela não seja limitada a definições finais e inflexíveis.

\section{Referências}

ARISTÓTELES. Poética. São Paulo: Imprensa Nacional, 2000.

ARRIGUCCI JUNIOR, Davi. Enigma e comentário: ensaios sobre a litera- 


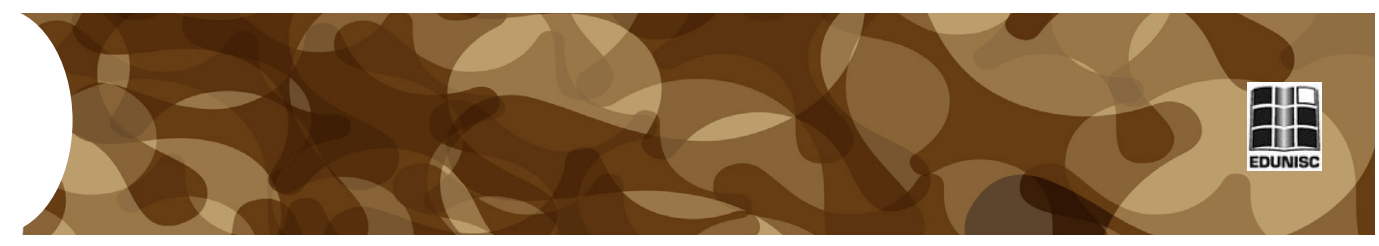

tura e experiência. São Paulo: Companhia das Letras, 1987.

BARTHES, R. O Rumor da Língua. São Paulo: Martins Fontes, 2004.

. Literatura e semiologia. Petrópolis: Editora Vozes, 1972.

BELTRÃO, Luiz. Jornalismo Opinativo. Porto Alegre: Sulina, 1980.

BENJAMIN, Walter. Magia e técnica, arte e política: ensaios sobre literatura e história da cultura. (Obras escolhidas; v.1). $7^{\mathrm{a}}$ ed. Tradução: Sérgio Paulo Roaunet. São Paulo: Brasiliense, 1994.

CANDIDO, Antonio. A crônica: o gênero, sua fixação e suas transformações no Brasil. Rio de Janeiro: Fundação Casa de Rui Barbosa, 1992.

CERTEAU, Michel. A invenção do cotidiano - vol.1: artes de fazer. $12^{\mathrm{a}}$. ed. Tradução: Ephrain Ferreira Alves. Petrópolis: Vozes, 1994.

COUTINHO, Afrânio. A Literatura no Brasil. Rio de Janeiro: Sul Americana, 1971.

FIGUEIREDO, Vera Lúcia Follain. Narrativas migrantes: Literatura, roteiro e cinema. Rio de Janeiro: Ed. PUC - Rio: 7 letras, 2010.

HUYSSEN, Andreas. Seduzidos pela memória: arquitetura, monumentos e mídia. Rio de Janeiro: Acoplano, 2000.

LEJEUNE, Philippe. O pacto autobiográfico: de Rousseau à Internet. Belo Horizonte: Editora UFMG, 2008.

MOTTA, Luiz Gonzaga. Análise crítica da narrativa. Brasília: Editora Universidade de Brasília, 2013.

REIS, Marco Aurelio. O subúrbio feito letra: o cotidiano da periferia em crônicas ácidas e carnavalizadas. 2015. Tese (Programa de Pós-Graduação Ciência da Literatura - Doutorado) - Universidade Federal do Rio de Janeiro, Rio de Janeiro, 2015.

RESENDE, Beatriz (Org.). Cronistas do Rio. Rio de Janeiro: José Olympio Editora, 2001.

RUFFATO, Luiz. A literatura segundo Luiz Ruffato. Entrevistadora: J. Resende Rocha. Belo Horizonte, 2007. Entrevista disponível em: http://www.periodicos.letras. ufmg.br/index.php/cesp/article/viewFile/6605/5605. Acesso em: 27 jun. 2016.

A biblioteca que virou pó. Jornal El País, Madri, 11 fev. 


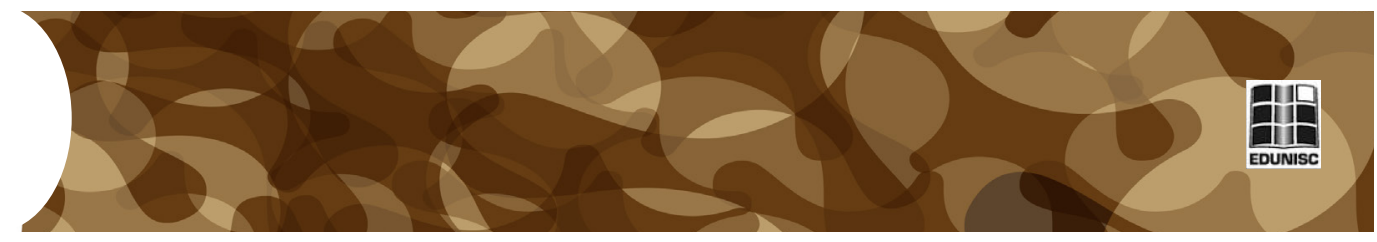

2014. Disponível em: http://brasil.elpais.com/brasil/2014/02/11/opinion/1392147444_004416.html. Acesso em: 10 ago. 2016. 2014.

. O dia mais triste da minha vida. Jornal El País, Madri, 31 mar. 2015. Disponível em: http://brasil.elpais.com/brasi1/2015/04/01/politica/1427839569_485118.html. Acesso em: 10 ago. 2016. 2015.

. Sabedoria vegetal. Jornal El País, Madri, 26 jan. 2015.

Disponível em: http://brasil.elpais.com/brasil/2015/01/26/opinion/1422275598_310805.html. Acesso em: 10 ago. 2016. 2015a.

. Sinto falta. Jornal El País, Madri, 17 fev. 2016. Disponível em: http://brasil.elpais.com/brasil/2016/02/17/opinion/1455706789_175637. html. Acesso em: 10 ago. 2016. 2016a.

. Voando pelos ares. Jornal El País, Madri, 01 abr. 2014. Disponível em: http://brasil.elpais.com/brasil/2014/04/01/opinion/1396382699_558407.html. Acesso em: 10 ago. 2016.2014a.

SALLES, Cecília Almeida. Orelha do livro. In: RUFFATO, Luiz. Mamma, son tanto Felice: Inferno Provisório - Volume I. São Paulo: Editora Record, 2005.

SANTIAGO, Silviano. Nas malhas da terra: ensaios. Rio de Janeiro: Rocco, 2002.

SILVA, Juremir Machado. Muniz Sodré, um pensador da comunicação no Brasil. Jornal O Correio do Povo, Porto Alegre, 19 abr. 2012. Disponível em: http://www.correiodopovo.com.br/blogs/juremirmachado/2012/04/2533/muniz-sodre-um-pensador-da-comunicacao-no-brasil/. Acesso em: 08 ago. 2016.

SODRÉ, Muniz. A narração do fato: notas para uma teoria do acontecimento. Petrópolis: Vozes, 2009.

SOSTER, Demétrio de Azeredo. Dialogia e atorização: características do jornalismo midiatizado. In: ENCONTRO NACIONAL DE PESQUISADORES EM JORNALISMO, 11., 2013, Brasília. Anais... Brasília: Universidade de Brasília, 2013. Disponível em: http:// http://soac.unb.br/index.php/ ENPJor/XIENPJOR/paper/download/2515/566. Acesso em: 29 out. 2016.

THOMÉ, Cláudia. A. Literatura de ouvido: crônicas do cotidiano pelas ondas do rádio. Curitiba: Appris, 2015. 